\title{
Work-Related Health and Safety Challenges of Rice Irrigation Farmworkers
}

\author{
L. Asamani
}

\section{ABSTRACT}

\begin{abstract}
Workers in the agricultural sector face several work-related health and safety challenges, similar to what workers in other high-risk sectors experience. However, there is a dearth of research efforts in the informal agricultural sector regarding the health and safety of farmworkers. The present paper explored the common work-related health and safety challenges that rice farmworkers in major irrigation schemes in southern Ghana experienced. The paper also explored the attitude and extent of personal protective equipment usage among rice farmworkers. Data were obtained from 11 key informants selected from three irrigation schemes and transcribed verbatim for analysis. Analysis of the data involved theoretical thematic analysis of Braun and Clarke. The analysis showed that rice farmworkers experienced several work-related health issues, injuries, and disorders, including cutlass injuries, lower back disorders, and malaria. It was also observed that the farmers were not using appropriate personal protective equipment. The implications of the findings were discussed and practical recommendations were made to help improve the safety and wellbeing of rice farmworkers.
\end{abstract}

Keywords: convenience safety violation, informal agriculture, irrigation farmworkers, work-related lower back disorder.

\section{INTRODUCTION}

\section{A. Background}

Agricultural work involves doing several tasks at different places on the farm and around the farm every day, and this has enormous health and safety implications for the farmworkers and their families. International Labour Organisation (ILO, 2014) observed that agricultural workers experience the broadest and most extensive exposure to injuries and diseases more than any occupation worldwide. There are several aspects of agricultural work that present health and safety threats to farmworkers. These include exposure to extreme weather conditions, exposure to animals, reptiles and plants, the use of chemicals, awkward working postures, prolonged working hours, sharp implement use, among others (Hardke \& Sadaka, 2013).

Hardke and Sadaka's observation supports Gupta and Joshi's (2002) position that farming activities require the intensive use of muscles, bones, joints, and sustained awkward positions on a daily basis. Aside from the awkward long sustained bending posture, rice farming involves muddy passageways, the use of unsafe bridges in transportation to and from the farm, and the usage of heavy hand tools, etc. These have the potential of causing muscular-skeletal disorders such as aches and pains in the limbs, joints or back, physical fatigue, injuries, and accidents.

Rice production starts with land preparation, then cropping, crop management, harvesting, and post-harvesting activities. The study, therefore, explored the major health and safety challenges associated with equipment use, agrochemical use, ergonomic and physical hazards involved in these stages of rice farming. Santaweesuk, Chapman, and Siriwong (2013) in a study that investigated health risk perception of occupational hazards among rice farmers in Nakhon Nayok Province, Thailand observed that paddy fields with holes, flooded areas, and mud make rice farmers more prone to accidents and injuries. Gupta and Joshi noted that water-rice fields are suitable places for the growth of several types of bacteria, viruses, fungi, mosquitoes, and other parasites. These may result in diseases like malaria, hookworm, skin diseases, etc. There are also respiratory diseases attributable to dust and fumes from field preparation and harvesting, moulds and other organic antigens, smoke from burning rice stubbles, and agrochemicals.

The use of chemical agents and other substances in crop management such as fertilizers, herbicides, and pesticides also present enormous hazards to the farmworkers. It has been found that human occupational exposure to pesticides is a significant cause of death worldwide (Gupta \& Joshi, 2002). Gupta and Joshi again suspected exposure to pesticides to have contributed to serious long-term and chronic health hazards. World Health Organisation (2000) estimates indicate that there are at least three million acute, severe cases of pesticide poisonings, and 20,000 unintentional deaths each year related to pesticide use in agriculture worldwide.

Rice farming in Ghana involves extensive manual activities and the use a wide variety of agrochemicals in their crop management processes. Asamani (2020) found that rice farmworkers are exposed to various safety hazards, including the use of agro-chemicals, tree stumps, slippery bonds, broken snail shells in the rice field, among others. The use of 
PPE, such as respiratory devices, wellington boots and goggle could prevent or minimise some of the possible adverse effects of exposure to these hazards on the health of the farmers. Nyatuame and Ampiaw (2015) also observed in their study with rice farmers of Afife Rice Irrigation Scheme in the Volta Region of Ghana that most of the farmers did not use any PPE, leading to various forms of injuries and health challenges. The current study also explored the attitude of the rice farmworkers toward the use of PPE, in addition to the common health and safety challenges they encountered.

\section{B. Statement of Problem}

Agriculture has been cited as among the most hazardous occupations in the world (ILO, 2010). The US Janklow Law Firm (2015) observed that farm accidents are a source of worry to many families of farmworkers and that similar to working in an office or at a store; agricultural workers have the same right to safety and peace of mind while on the job. Fatal accident rates in many countries indicate that the rate in agriculture is twice the average for all other sectors. The International Labour Organisation (2000) estimates indicate that out of a total of 335,000 fatal workplace accidents worldwide, there were about 170,000 deaths among agriculture workers.

The US Bureau of Labour Statistics (2012) also indicated that agriculture ranks among the most hazardous industries and farmers are at very high risk for fatal and nonfatal injuries, with farming and ranching jobs ranked in the top ten of the most dangerous occupations in the United States. The statistics further showed that 374 farmers and farm workers died from a work-related injury, resulting in a fatality rate of 20.2 deaths per 100,000 workers in the US. The 2011 statistics of the US Bureau of Labour Statistics also indicated that there were 25.4 deaths per 100,000 workers in agriculture, while mining, construction, and transportation recorded 12.8, 9.3, and 11.0 deaths respectively. The 2017 data of deaths per 100,000 indicated that driver/sales workers and truck drivers' death per stood at 26.8, with that of farmers, ranchers and other agricultural managers being 24.0, first-line supervisors and construction trades and extraction workers, 21 and grounds maintenance workers being 18.7 (Bureau of Labour Statistics, 2018). Bennett (2013) also reports that agriculture was ranked number 8 in Bankrate's ratings of "The 10 of the most dangerous jobs" in the US.

Mock, Adjei, Acheampong, Berbo and Simpson (2005) reported that, among rural workers, farming represents $71.6 \%$ of reported work-related injuries in Ghana. McNeill and O'Neill (1998) earlier found lower back pain (77\%), musculoskeletal disorders $(76 \%)$, and burns $(50 \%)$ to be the most safety incidents reported among Ghanaian farmworkers. Other farm safety researches among cocoa farmers (Bosompem \& Mensah, 2012; Muilerman, 2013) also observed that farmworkers encountered myriads of injuries and disabilities from the farming operations. It is worth noting that the agricultural sector is the mainstay of the Ghanaian economy and employs over 64\% of Ghanaians (Sharife, 2011). This means that research efforts should be directed at the sector that is the pivot of the economy.

The prime aim of this paper was to explore health and safety challenges that the rice farmers encountered in their activities through a qualitative approach. There is a dearth of information regarding safety hazards and health and safety incidents that rice farmers are exposed to in their activities in Ghana. There was some information in the literature about hazards and injuries in cocoa farming (e.g. Bosompem \& Mensah, 2012), but little is known about rice farming health and safety challenges in Ghana. Indeed, Bosompem and Mensah (2012) indicated that very little research attention has been given to occupational hazards and safety challenges of cocoa and other farmworkers. They noted further that only a few studies investigated hazards associated with the use of agrochemicals, but ignored the hazards associated with other farming activities. I have also observed that the safety challenges of rice farming, in particular, have been largely neglected, yet rice is one of the most consumed cereals in Ghana. The study, therefore, explored the safety challenges that rice farmers face, together with their attitude toward personal protective equipment usage.

\section{Specific objectives}

The specific objectives of the paper were to explore:

1. common health and safety challenges that rice farm workers in Southern Ghana experience.

2. attitude toward personal protective equipment/wears usage among the rice farm workers.

\section{Methods}

\section{A. Methodological Approach}

The study employed a qualitative approach to explore the common health and safety incidents, and the attitude toward the use of personal protective equipment among the rice farmworkers. Creswell (2007) defines qualitative research as "a means for exploring and understanding the meaning individuals and groups ascribe to social or human problems" (p. 5). Patton (1990) intimated that the qualitative research approach enables researchers to get close to the problems throughout the fieldwork and brings their understandings and experiences into any recommendations that may emerge from the data collected. The use of a qualitative approach made it possible for observations and interviews to be conducted and responses recorded directly without any obstacles from the participants (Hair, Bush \& Ortinau, 2000).

\section{B. Sample and Sampling Procedure}

The sample consisted of key informants from three major rice irrigation schemes from the Central and Greater Accra Regions of Ghana. The sample included scheme managers, supervisors (or extension officers), and some rice farmworkers. The theoretical sampling procedure was employed, not seeking a perfect representation of the respondents under study, and the sample was made purposefully, focusing on key informants to the needed information rather than randomly (Ezzy, 2002). Two former Scheme Managers who were also engaged in rice farming, and one incumbent Scheme Manager, together with one extension officer each from two of the Schemes were selected. The other scheme did not have an extension officer at the time of the study. Three respondents were selected from each of the schemes, making a total of 11 respondents. 
TABLE I: CHARACTERISTICS OF INTERVIEW RESPONDENTS

\begin{tabular}{ccccc}
\multicolumn{5}{c}{ TABLE I: CHARACTERISTICS OF INTERVIEW RESPONDENTS } \\
\hline RP & Sex & Age & Status & Education \\
\hline 1 & Male & 62 & $\begin{array}{c}\text { Ex-scheme Manager/ } \\
\text { Farmer }\end{array}$ & First degree \\
2 & Male & 61 & $\begin{array}{c}\text { Ex-scheme Manager/ } \\
\text { Farmer }\end{array}$ & First degree \\
3 & Female & 39 & Extension Officer & First degree \\
4 & Male & 41 & Scheme Manager & First degree \\
5 & Male & 32 & Extension Officer & Diploma \\
6 & Male & 43 & Rice Farmer & Middle School \\
7 & Male & 54 & Rice farmer & Middle School \\
8 & Male & 34 & Rice Farmer & SHS \\
9 & Male & 68 & Chief Farmer & Middle School \\
10 & Male & 65 & Rice Farmer & Middle School \\
11 & Female & N/A & Rice Farmer & Middle School \\
\hline
\end{tabular}

\section{Data Collection Instrument}

Semi-structured interview guide and observation, to confirm some of the responses, were used to collect the data. Interviews and personal observations were considered most appropriate for obtaining relevant information regarding rice farm health and safety problems and the use of PPEs. The interview guide consists of 10 open-ended questions, and follow-up/probing questions were asked where necessary to get further details and clarifications, as suggested by (Burnell, 2007; Creswell, 2007; Warren, 2001). The interview guide sought to find out the health and safety challenges the farmers encountered at the pre-planting stage (land preparation and nursing: three questions), planting stage (one question), crop management stage (three questions), harvesting (one question) and post-harvesting stages (two questions).

The interview guide was designed through a critical review of pertinent literature on rice farming, taking cognizance of the research objectives. Several research databases were used, including ProQuest, Google Scholar, PubMed, EBSCOhost, JStor, ScienceDirect, etc. Experienced rice farm workers reviewed the items generated and offered suggestions, which were incorporated in obtaining the final 10 items with relevant probes, as indicated earlier.

\section{Data Collection Procedure}

The interviews were conducted mainly in the English Language and audio recorded since all the respondents obtained at least a basic level of education and could speak the English Language. During the interviews and visits to the farm sites, observations were also made to see how the farmers carried out their farming activities and these were recorded in a notebook. The interviews were recorded and observation and interaction notes were also taken since recording equipment can fail or may not play as proposed by Creswell (2007).

Follow-up questions were used to probe and clarify interviewee's responses as suggested by Warren, (2001) and Burnell (2007). Each interview lasted between 35 to 45 minutes. At the end of the entire interview, random portions of the tapes were played back for participants to verify the authenticity and also ensure the validity or trustworthiness of the data. All the participants confirmed what was played was a true reflection of what they intended to say. In a few cases, the respondents added new information they felt was relevant.

\section{E. Data Analysis Procedure}

Attride-Stirling (2001) emphasized the importance of qualitative Psychologists including how they analysed their data in the final report of their study. Given that there were specific research objectives for this study, the theoretical (deductive) thematic analysis (Patton, 1990) was used to analyse the data. Braun and Clarke (2008) indicated that thematic analysis is not linked to any pre-existing theoretical framework and so could be used within different theoretical frameworks.

The audio-recorded interviews were transcribed verbatim and the six-step thematic analysis of Braun and Clarke (2008) was used for the analysis. The analysis process was analystdriven, guided by the theoretical and analytical interest of the paper as suggested by Braun and Clarke (2008). Data collection, analyses, and coding were done in line with the research objectives. Themes were then identified and organised mainly at the semantic or explicit surface meaning of the data, focusing mainly on what the participants had said (Braun \& Clarke, 2008).

\section{FINDINGS}

\section{A. Major Forms of Health and Safety Challenges}

The first objective of the paper was to find out common health and safety challenges that the rice farmers experienced. The findings are presented with excerpts from the interview transcripts.

One of the most common safety concerns was that the farmworkers frequently experienced injury by objects in the soil. This is because the farmers generally were not wearing Wellington boots or paddy boots when transplanting or working on the rice field. This is what one of the respondents (RP 2) had to say regarding the wearing of Wellington boots: "It is too heavy and cannot be used in the mud; water may even enter it. We go barefooted. ...Sometimes you step on objects in the soil and get injured. There are snail shells and other objects at some places". Another respondent also said: "Sometimes you see these snails? (Showing me a sail on the farm), the dead ones; their shells cut the sole of the feet, but not often" (RP 1). Respondent RP 4 also indicated that: "Sometimes, you step on something in the soil and get injured. Sometimes there are snail shells or other objects that injured some of the farmers."

Another health challenge experienced by the farmers was foot rot. Most of the farmers use normal shoe socks to hold the bars of the pair of trousers to facilitate their movement This process keeps the feet constantly wet and stacked together, leading to foot rot. The following is an excerpt from one of the respondents. "I wear ordinary socks to hold the pair of trousers in place. That is what many of the farmers do. It gets wet and muddy, but you wash it after work. Some people get foot rot and we are also bitten by ticks in the water. There are also snail shells in the soil that cuts the sole. So the socks help to prevent some of those, though it is not appropriate" (RP 9). This respondent also emphasised the earlier assertion that the farmers get injured by certain sharp objects in the soil, in addition to the rotting of feet.

The farmers also reported experiencing fertilizer burns and had chemicals blown into their eyes and nostrils. This 
usually happens during fertilizer application and spaying of weedicides and other chemicals. Respondent (RP 8) indicated that, during the application of fertilizers, “... water makes the fertilizer wet, so when it is wet it causes burns and irritation of the skin. Respondent (RP 8) also indicated that the wind sometimes blew chemicals into their eyes and nostrils during fertilizer application and spraying of weedicides and other pest control chemicals. He reported: "It's very serious. So some people use goggles and there is something... nose pad. But most of us don't use it. We check the direction of the wind."

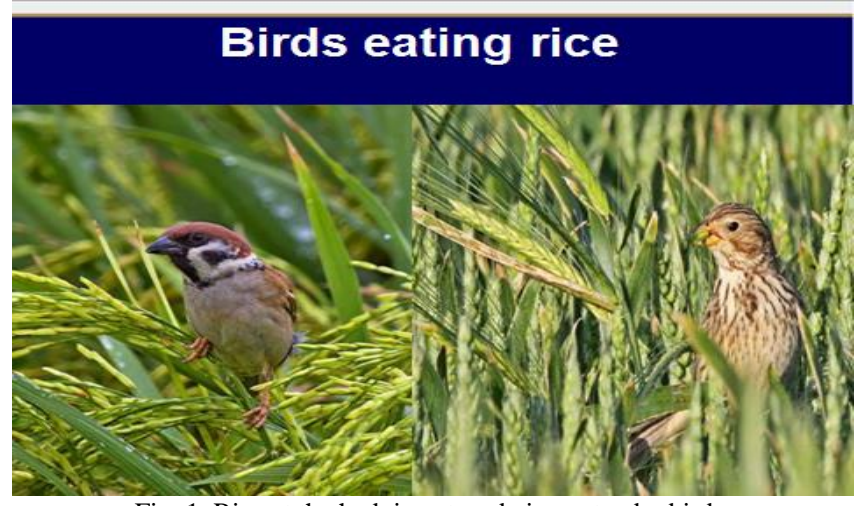

Fig. 1. Rice at the hedging stage being eaten by birds. Source: https://www.google.com.gh/search.

The farmers engage in an activity they referred to as "scaring". This involves screaming and using a catapult and other means to drive away birds that eat the hedging paddy rice, as the farmers wait for the rice to mature and try for harvesting. This is a critical stage in rice farming in Ghana. If the farmers do not put in a rigorous measures, including the use of fishing nets to cover the entire rice field, the birds would eat everything, and they would have nothing to harvest. The sore throat was another common challenge among the rice farmworkers at this stage. An excerpt from the interview transcript indicated that the farmers experienced sore throat as a result of the way they had to scream to scare the birds that eat the fresh growing paddy rice. This is what the respondent (RP 2) said: "Sore throat has become a normal part of our work during the scaring period because it is very common due to the screaming". Another respondent said: "Yea! A lot of the times, we experienced sore throat" (RP 10); and "The moment you get home, you have to go and get some medicine to treat it. It is very serious. It's one major problem for us" (RP 6).

The rice farmers also use the catapult to drive away from the birds during the period of scaring, and this had caused injuries to a number of them. Catapult injuries were reported by a number of the farmers and confirmed by all of them. According to one respondent: "The catapult can get torn and the stick or the rubber can hit your chest or any other place. We even get injured sometimes (RP 10). "Sometimes the catapult gets torn and hits our chest, head, eye, etc. Someone even had the eye damaged by the catapult" (RP 5). Another respondent had this to say: "We use the catapult for scaring; it got torn and hit me several times. We get injured in some cases" (RP 6). (He showed me a scar on his forehead that resulted from catapult wound).

A follow-up was to meet the farmer whose eye was damaged by the catapult. He happened to be one of the experienced rice farmers and so was selected to be part of the respondents. He explained how the eye got damaged in these words:

\begin{abstract}
"...As I stretched the catapult, it slipped from my hands and the stick came to hit my eye. The eye was injured and blood started flowing. Some of my people helped me and gave me first aid. I later went to the clinic in Ashaiman (a nearby town) and was asked to report another time. But I did not have money to continue the treatment. Meanwhile, I was coming to the farm, with the hope of harvesting to have some money to continue the treatment. Unfortunately, by the time I harvested and went back to the hospital, I was told the eye was permanently damaged. Now I don't feel the pain, but the eye is spoilt. I use the other one to see" (RP 9).
\end{abstract}

The scaring of birds (bird management) also comes with another danger to the farmers, slip, and falls. The farmers usually have to run on the bonds in the rice fields while chasing the birds, screaming and throwing of stones, using the catapult and other means. It thus, happens that while they run up and down, they slip and fall a lot of the time. This is how respondents (RP 5) put it: "When running on the bond to scare birds you can slip and fall, or stumble in a whole on the ground and fall. We fall all time."

After the farmers harvest their rice, the farmers have to winnow and thresh the rice. At this stage, the farmers complained of having dust and particles falling on their eye, as respondents (RP 9) indicated: "Dust from winnowing enters our eyes very much". The farmers also complained of skin problems. For instance, a respondent observed: “... The rice itches very badly. By the time we finish threshing or winnowing, if I don't take care I would have rashes all over my hand. That is why you can see some people are wearing long sleeve dresses and shirt” (RP 7).

The farmers use cutlasses during the initial land preparation and harvesting of the rice. Most of the farmers do manual harvesting, using the cutlass, and cutlass injuries have been common occurrences in their work. This is an excerpt from two respondents: When we use the cutlasses to weed, sometimes we experience cutlass wounds; you also get blisters in the palm (RP 2). Another respondent: "Sometimes, the cutlass cuts you when harvesting the rice manually. Especially, during manual harvesting of rice with a cutlass, frequently farmers cut their hands or legs" (RP 7).

\section{Transplanting of rice seedlings}

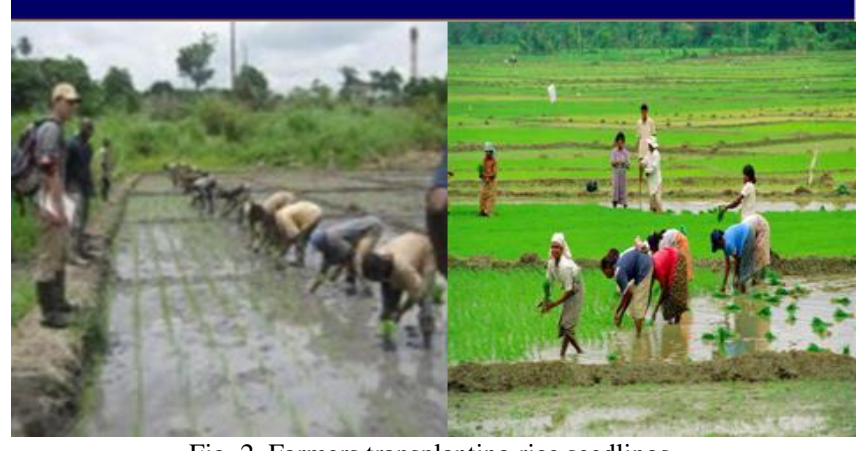

Fig. 2. Farmers transplanting rice seedlings Source: https://www.google.com.gh/search. 
The processes of land preparation, planting (which is mostly done manually), and manual harvesting and other processes require the farmers to be in a flexed/stooped posture for hours. This, among other factors, exposed the farmworkers to work-related lower back disorders. As Fathallah, Miller, and Miles (2008) observed, the lower back disorder was common among the rice farmers. The farmers reported having consistent and persistent body pains and extreme fatigue because of long and tedious working hours. For instance, a respondent indicated, "For me, I can work for even the whole day without resting. We farmers do not have a rest or break period, especially during the scaring period. You continue working; when you are tired then you come and rest for a while; you take a little rest then you go and continue the work. But during scaring time, no rest, else the birds would eat all the rice. By the time you close, you get very tired and feel pains all over your body" (RP 5).

Headache and fever from exposure to direct exposure to the sun were very common among the farmworkers. A 54year-old male farmer indicated that the farmworkers, usually, do not have any form of protection from the sun while working on the rice field. He noted that only a handful of the farmers wear caps or hats while working. He reported: "I don't use anything, but some people wear a cap. Because we work in the direct sun for many hours, we sometimes get headaches and fever" (RP 6).

The farmers also reported that malaria was a common occurrence and a major challenge for them. They noted that the swampy nature of the rice field made it convenient for mosquitoes to breed. The following is an extract from one of the respondents: "There are more mosquitoes here than any other town. Everywhere rice is grown, there are a lot of mosquitoes there and they give us malaria. So we have a clinic here. Because of the mosquitoes, the community requested the government and they provided us with a clinic. So the moment anyone gets injured or falls sick, or suffers any other problem, we take the person to the clinic" (RP 8).

Table II presents a summary of the major health and safety challenges that the rice farmworkers reported.

\section{B. Use of Protective Equipment or Wears}

The second objective of the paper was to explore the attitude of the farmers regarding the use of personal protective equipment (PPEs) or protective wears, the appropriate usage. In a hazardous work environment such as rice farming, most of the hazards cannot be eliminated, and the need for safety and protective measures becomes imperative. The use of PPE becomes critical in those circumstances to avoid any harm or injury. It is important to note that the presence of hazards does not automatically translate to harm; appropriate protective and preventive measures are required to prevent the hazard from causing harm.

The findings from this study indicated that a number of farmworkers either did not use any form of protective equipment/wear, or they did not wear the appropriate ones. The use of inappropriate safety wears, or non-usage could result in unintended consequences. For instance, the use of shoe socks to hold a pair of trousers in a paddy field has resulted in foot rots, as indicated above among the rice farmers.
TABLE II: SUMMARY OF MAJOR RICE FARM HEALTH AND SAFETY CHALLENGES

Major Health and safety challenges; with excerpts from the transcripts

Injury by objects in the soil

We go barefooted. ...Sometimes you step on objects in the soil and get injured.

Footrot: Some people get foot rot and we are also bitten by ticks in the water.

Fertilizer burns: Water makes the fertilizer wet; so when it is wet it causes burns and irritation of the skin.

Chemicals blown into eyes and nose:

The wind sometimes blew chemicals into the eyes and nostrils during fertilizer application and spraying of weedicides

\section{Sore throat:}

Sore throat has become a normal part of our work during the scaring period because it is very common due to the screaming; A lot of the times, we experienced a sore throat

Dust or particles falling on the eye:

Dust from winnowing enters our eyes very much

\section{Skin irritation and rashes:}

The rice itches very badly. By the time we finish threshing or winnowing, if I don't take care I would have rashes all over my hand.

\section{Injuries from catapults}

The catapult can get torn and the stick or the rubber can hit your chest or any other place. We even get injured sometimes. "Sometimes the catapult gets torn and hits our chest, head, eye

\section{Slip and falls:}

When running on the bond to scare birds you can slip and fall, or stumble in a whole on the ground and fall. We fall all time.

\section{Cutlass injuries:}

During manual harvesting of rice with a cutlass, frequently farmers cut their hands or legs

\section{Body pains and extreme fatigue:}

But during scaring time, no rest, else the birds would eat all the rice. By the time you close, you get very tired and feel pains all over your body

Headache and fever from exposure to the direct sun:

Because we work in the direct sun for many hours, we sometimes get a headache and fever

\section{Lower back (waist) pain:}

We do get back pains because of the stooped posture when clearing the land or harvesting with a cutlass

\section{Malaria:}

There are more mosquitoes here than any other town. Everywhere rice is grown, there are a lot of mosquitoes there and they give us malaria.

The farmers indicated that they mostly did not wear Wellington boots to the farms: "We don't use it; if I tell you the truth; we wear normal socks" (RP 1). The practice observed among the rice farmers was that most of them wear socks in bathroom slippers, instead of the Wellington boots. When they are in the paddy field, the slippers are removed, because they would get stacked in the field. The wearing of socks had therefore been the norm, instead of the paddy boot. Another respondent said: "Here we normally work barefooted. The Wellington boot is too heavy for the mud. The Japanese gave us paddy boot some years back, which we used some time ago but they are spoilt now. It is very light and comfortable in the field. There is none around to buy here (RP 2). Respondent (RP 9) also reported that: "I wear ordinary socks to hold the pair of trousers in place. That is what many of the farmers do. It gets wet, but you wash it after work" (RP 9).

In another development, I asked a farmer winnowing rice where a lot of particles and dust were flying all over the place from the winnowing machine why he was not using the 
goggles to protect his eyes. He responded that he did not have any. When asked if he would use it if he had one, this was his response: Yes, but I don't have. You need to use your own money to buy it. This together with gloves, and long sleeves if I get I would use. You need to use protective clothing and gloves, those too we don't have (RP 6). Thus, it appears that the majority of the rice farmers did not use appropriate protective wears even though they were aware of the health and safety implications. Availability of the PPEs, the cost, and the feeling that the PPEs would inconvenience them were some of the reasons they cited for the non-usage.

Some of the farmers said they relied on their experience during farming activities. For instance, spraying of weedicides and other agrochemicals could be very hazardous. Some farmers indicated that the chemicals are sometimes blown into their eyes, and they inhale the same. Meanwhile, they felt it was not critical for them to use appropriate PPE. One of the respondents admitted that the extent to which the chemicals enter their eyes or nostrils were very serious: "It's really serious. So some people use goggles, and there is something... nose pad. But most of us don't use it. We check the direction of the wind (RP 8).

The attitudes and some of the reasons that explains why the rice farm workers in Southern Ghana largely violated health and safety work procedures are presented in Table III.

TABLE III: PERSONAL PROTECTIVE EQUIPMENT/WEAR USAGE PPE Usage

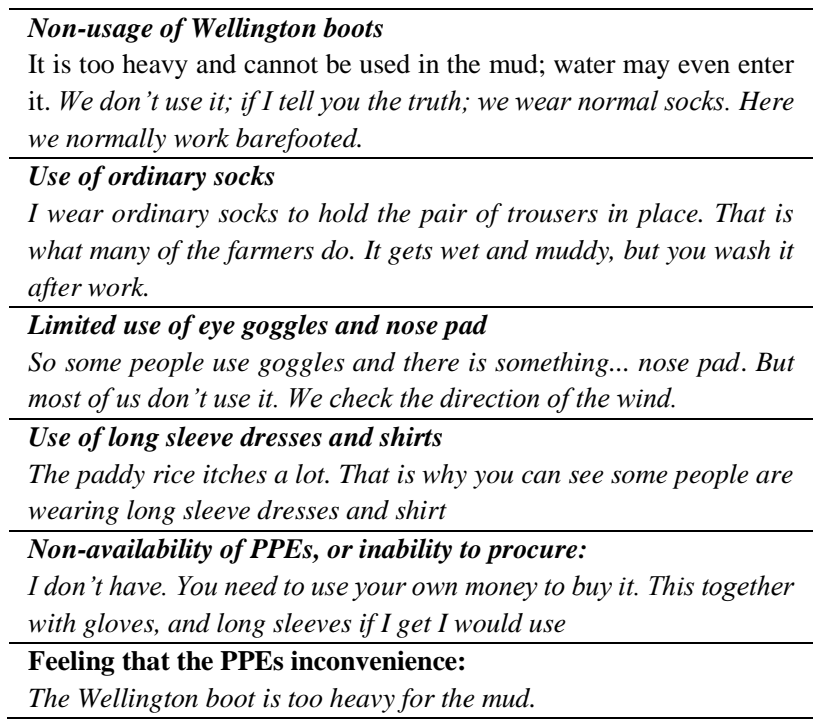

\section{DISCUSSION OF FINDINGS AND CONCLUSIONS}

The findings indicate clearly that farming activities pose a lot of problems to farmer workers because of the tedious and muscular nature of the work (Gully et al, 2002). The rice farming activities that posed most health and safety challenges to the farmers were the scaring of birds, using the catapult, and the manual harvesting and threshing of rice. There are other features or aspects of farming that are inherently hazardous to the health and safety of the farmworker, such as long working hours, weather conditions, etc. Gupta and Joshi (2002) indicated that farming has the potential to cause muscular-skeletal disorders, aches, pains, etc. As far back as 1989, McNeill and O’Neill investigated the health and safety of farmers engaged in crop production and observed many disabilities among the farmers, including lower back pain, chest pain, cutlass injuries, etc. Other research conducted in Ghana among Cocoa farmers reported similar safety concerns (Bosompem \& Mensah, 2012; Muilerman, 2013).

The long working hour is prevalent among the rice farmers in this study. As reported by some of the respondents, it is not possible to rest during the bird management period (scaring of birds). This is because if one leaves the farm to rest, the birds would consume all the rice. The ILO (2010) observed that long working hours is one of the main causes of health challenges in farming. The Jacklow law firm (2015) also indicated that the common types of farm injuries result from equipment and implement use, pesticides, and chemical poisoning, fertilizer burns, etc. These were corroborated in the current study with the rice farmers.

Despite the prevalence of various forms of hazards, it was observed that a great number of the farmers did not wear appropriate PPE. Consequently, they experience many safety and health challenges. Meanwhile, it seems that the farmers were used to, and had become accustomed to the unsafe ways of working. This observation corroborates Pyykkönen and Aherin's (n.d) observation that risk management principles are not widely used in agriculture. It was observed in the current study that many of the rice farmers acted in an unsafe manner, even though they were aware of the health and safety implications. Workplace inspection, accident investigation, and social science research in the US indicate that there is a deep-seated culture of unwise risk-taking among farmworkers. Farmers also often are resistant to officialdom and perceive safety regulations and procedures as a great burden (Pyykkönen \& Aherin, n.d).

Regarding why they were not using the PPEs and other safety measures, some of the rice farmers indicated that the appropriate PPE and protective wears were not available for them to buy and use. Other farmers found the protective wear uncomfortable and inconveniencing for their productive activities. This suggests that they placed productivity above safety and engaged inconvenient safety violations.

This paper conceptualised safety violation as any form of unintentional, accidental, or deliberate deviations from the safety work rules, procedures, instructions, and regulations that would help to prevent work accidents, harm to individuals, loss of life, and damage of equipment. The finding in this paper indicates that the rice farm workers violated and ignored safe work procedures because they felt that the use of appropriate health and safety equipment (e.g. Wellington boots) may not be comfortable or convenient for them. This, therefore, makes them violate safe work procedures for the sake of their convenience and comfort, a situation referred to here as a convenient safety violation. HSE (1995) noted that individuals mostly violate safe work procedures as a result of a genuine desire to perform work satisfactorily given the constraints that the use of PPE may pose.

To sum up, the findings revealed the need for intensive education and awareness creation about the importance of the use of appropriate PPEs since most of the hazards are inherent in the farming processes and cannot be eliminated. Suutarinen (2003) indicated that scientific contributions on the 
application of formal safety management theories or practices in farming are not commonly available. This suggests that more empirical research and attention should be given to the agriculture and the informal sector as Ghana desires to ensure food security and create employment avenues for the youth in the agricultural sector. Literature indicates that occupational health and safety has not been generally regarded as an integral issue of good farm management yet (HSE, 2009). But Ghana can take the lead and make good farm safety management a major concern, more so because agriculture is the backbone of our economy.

\section{PRACTICAL IMPLICATIONS AND RECOMMENDATIONS}

Ghana has great potential to increase rice production to help reduce the level of rice importation. To achieve this goal, the health and safety of rice farmers are crucial. The health and safety of rice farmers and other production agriculture workers need to be taken seriously if Ghana seeks to ensure productive workforce and healthy nation because the agriculture sector employs over $60 \%$ of Ghanaians. Just like working in a factory, office, or a store, agricultural workers have the same right to safety and peace of mind while on the job. For this reason, the Directorate of Occupational Health and Safety needs to extend their education and inspections activities to the informal and production agricultural work settings.

The farmers must also take personal responsibility for their safety and well-being. The Scheme Manager, extension officer, leadership of the farmers' Co-operatives should all take the safety and well-being of the farmworkers seriously and show commitment to ensure the safety of all workers. Safety education programmes and drills can be organised regularly, for instance, twice in a year. Also, the Co-operative executive should make appeals to the government to facilitate the supply of appropriate PPEs for their members. Emphasis must not be placed on high productivity at the expense of the safety and well-being of the workforce. The safety and health of the workers must be made a top priority by the scheme managers, the extension officers, and the executives of the Co-operatives.

\section{Limitations AND SUGGESTIONS FOR FUTURE STUDIES}

The study was conducted in the Southern part of Ghana and with only organised rice irrigation scheme farmers. This may limit the generalizability of the findings to rice farmers at the other parts of Ghana, given the relevance of contextual variables in influencing safety behaviour and safety outcomes. Again, the health and safety situation of nonorganised rice farmers may be different from those in the organised farms. Also, given that this study was conducted among only rice farmers, the findings may have limited applicability to other production agricultural ventures and industry.

Future studies should take explore these issues among small-holder rice farmers, and follow it up with a survey with a larger sample to find out how widespread the work-related health and safety challenges are among the small-holder and irrigation farm workers as well. Other studies could also investigate the health and safety challenges among other categories of farm workers. This would bring about a comprehensive appreciation of the health and safety challenges among farm workers to inform policies and interventions to protect the wellbeing of farmers in Ghana, and similar contexts.

\section{ACKNOWLEDGEMENT}

My sincere gratitude goes to the rice farmers, their Cooperative executives, and the Scheme managers for their support in providing data for this paper. I also want to thank the University of Cape Coast for providing funding for the study from which the paper was extracted. My Teaching Assistant, Miss Sarah Takyi, and former Teaching Assistant, Miss Esther Addae, for their assistance in the typesetting of the paper.

\section{REFERENCES}

Asamani, L. (2020). Occupational health and safety hazards in rice farming in Ghana. European Journal of Business and Management, 12(21), 8090.

Attride-Stirling, J. (2001). Thematic networks: An analytic tool for qualitative research. Qualitative Research, 1(3), 385-405.

Bennett, C. (2013). Death on the farm a grim reality of agriculture, retrieved May 27, 2015, from http://westernfarmpress.com/blog/death-farmgrim-reality-agriculture.

Bosompem, M., \& Mensah, E. (2012). Occupational hazards among Cocoa Farmers in the Birim South District in the Eastern Region of Ghana. ARPN Journal of Agricultural and Biological Science, 7(12), 10551061.

Braun, V., \& Clarke, V. (2008). Successful qualitative research: A practical guide for beginners. London: Sage Publications.

Bureau of Labour Ststistics. (2018). Number and rate of fatal work injuries by industry sector, 2017. In: Census of Fatal Occupational Injuries, 2019. Washington, DC: Bureau of Labour Statistics. Available at https://www.bls.gov/charts/census-of-fatal-occupationalinjuries/number-and-rate-of-fatal-work-injuries-by-industry.htm

Bureau of Labour Statistics. (2012). Workplace injuries and illnesses - 2011 Washington, DC: Bureau of Labour Statistics.

Bureau of Labour Statistics. (2011). Fatal occupational injuries in 2010. The Economic Daily, Washington, DC: Bureau of Labour Statistics. Available at www.bls.gove/opub/ted/2011/ted 20110829.htm.

Burnell, B. (2003). The real-world aspirations of work-bound rural students. Journal of Research in Rural Education, 18(2), 104-113.

Creswell, J. W. (2007). Qualitative enquiry and research design: Choosing among five approaches. US: Sage publications Ltd.

Ezzy, D. (2002). Qualitative analysis: Practice and innovation. Crows Nest, NSW: Allen \& Unwin.

Fathallah, F. A., Miller, B. J., \& Miles, J. A. (2008). Low Back Disorders in Agriculture and the Role of Stooped Work: Scope, Potential Interventions, and Research Needs. Journal of Agricultural Safety and Health, 14(2), 221-245.

Gully, S. M., Incalcaterra, K. A., Gupta \& Joshi, A., \& Beaubien, J. M. (2002). A meta-analysis of team-efficacy, potency, and performance: interdependence and level of analysis as moderators of observed relationships. Journal of Applied Psychology, 87(5), 819-832.

Gupta, S. K. \& Joshi, M. P. (2002). Pesticide poisoning cases attending five major hospitals of Nepal. Journal of Nepal Medical Association, 41, 447-456.

Hardke, J., \& Sadaka, S. (2013). Arkansas Rice Production Handbook (pp.195-201). Ankansas: University of Arkansas Division of Agriculture. Available at www.uaex.edu/publications.

Hair, J. F., Bush, R. P., \& Ortinau, D. J. (2000). Marketing research: A practical approach for the new millennium. Irwin Professional Publishing.

Health and Safety Executive. (2009). Self-reported work-related illness and workplace injuries in 2007/08: Results from the labour force survey. Retrieved on January 20, 2017 from http://www.hse.gov.uk/statistics/lfs/lfs0708.pdf. 
Health and Safety Executives. (1995). Improving compliance with safety procedures reducing industrial violations. UK: The Human Factors in Reliability Group (HFRG). Retrieved from www.hse.gov.uk/humanfactors/topics/improvecompliance.pdf.

International Labour Organisation. (2014). Creating safety and healthy workplace for all. Report prepared for the G20 Labour and Employment Ministerial meeting, Melbourne, Australia. Retrieved from http://www.g20.utoronto.ca/2014/ILOsafe_and_healthy_workplaces.pdf.

International Labour Organisation. (2010). Global Employment Trends for Youth. Special issue on the impact of global economic crises on the youth. Geneva: Author.

International Labour Organisation. (2000). ILO guidelines on occupational safety and health management systems. Geneva: Author.

Janklow Law Firm (US). (n.d). Pain and suffering calculator. Retrieved July 8, 2015 from www.janklowabdall.com.

McNeill, M., \& O’Neill, D. (1998, April). Occupational disorders in Ghanaian subsistence farmers. In Proceedings of the annual conference of the Ergonomics Society. Loughborough, UK, Chartered Institute of Ergonomics and Human factors (1-3).

Mock, C., Adjei, S., Acheampong, F., Berbo, L., \& Simpson, K. (2005) Occupational Injuries in Ghana. International Journal of Occupational and Environmental Health, 11(3), 238-245.

Muilerman, S. (2013). Occupational safety and health on Ghanaian cocoa farms. Baseline report of sustainable tree crops programme, Accra, Ghana, International Institute of Tropical Agriculture (IITA).

Patton, M. Q. (1990). Qualitative evaluation and research methods. Newbury Park, CA: SAGE Publications Inc.

Pyykkönen, M. \& Aherin, B. (n. d). Occupational health and safety in agriculture, Helsinki, Finland: Ministry of Social Affairs and Health.

Santaweesuk, S., Chapman, R. S., \& Siriwong, W. (2013). Health risk perception of occupational hazards among rice farmers in Nakhon Nayok province, Thailand. Journal of Health Research, 27(3), 197 200.

Seale, C. (1999). Quality in qualitative research. Qualitative Inquiry, 5(4), $465-478$

Sharife, K. (2011). Ghana: Over 64\% work in agriculture sector, retrieved on $26^{\text {th }} \quad$ May, 2015 fromhttp://www.theafricareport.com/WestAfrica/over-64-of-employed-ghananians-work-in-the-agriculturalsector.html.

Suutarinen, J. (2003). Occupational accidents in Finnish Agriculturecausality and managerial aspects for prevention. MTT

Warren, N. (2001). Work stress and musculoskeletal disorder etiology: The relative roles of psychosocial and physical risk factors. Work, 17, 221234.

World Health Organisation. (2000). The world health report 2000: health systems: improving performance. World Health Organization. 